IRA-International Journal of Applied Sciences ISSN 2455-4499; Vol.03, Issue 03 (2016)

\title{
Induction of Herbicide resistance via seed- derived rice (Oryza sativa) Calli
}

\author{
E. M. S. I. Ekanayaka ${ }^{1}$, S. R. Weerakoon ${ }^{1}$, T. D. Silva ${ }^{2}$, S. Somaratne ${ }^{1}$ \\ ${ }^{1}$ Department of Botany, \\ The Open University of Sri Lanka, \\ P.O. Box 21, Nawala, Sri Lanka. \\ ${ }^{2}$ Department of Plant Sciences, \\ University of Colombo, \\ Colombo 03, Sri Lanka.
}

DOI: http://dx.doi.org/10.21013/jas.v3.n3.p15

\section{How to cite this paper:}

Ekanayaka, E., Weerakoon, S., Silva, T., \& Somaratne, S. (2016). Induction of Herbicide resistance via seed-derived rice (Oryza sativa) Calli. IRA-International Journal of Applied Sciences (ISSN 2455-4499), 3(3). doi:http://dx.doi.org/10.21013/jas.v3.n3.p15

(C) Institute of Research Advances

\section{(c) Br-No}

This works is licensed under a Creative Commons Attribution-Non Commercial 4.0 International License subject to proper citation to the publication source of the work.

Disclaimer: The scholarly papers as reviewed and published by the Institute of Research Advances (IRA) are the views and opinions of their respective authors and are not the views or opinions of the IRA. The IRA disclaims of any harm or loss caused due to the published content to any party. 


ABSTRACT
Herbicide resistant (HR) rice improves efficiency of weed management and HR
varieties can develop through induced mutagenesis. The present investigation was
focused on mutagenic response of seed-derived rice calli to different EMS
concentrations and evaluation for HR. Seed-derived calli were obtained from
glyphosate-susceptible rice variety $($ Bg250) and exposed to varying concentrations
of EMS $(0.1 \%, 0.2 \%, 0.3 \%$ and $0.4 \%)$. EMS treated calli were exposed to glyphosate
$(0.2 \%)$ and Tetrazolium test $(1 \%$ TTC) was applied to identify cell viability in calli.
Fluorescent AFLP analysis was performed on EMS treated calli. Results indicated
that mutation of calli was higher at EMS concentration range of $0.1-0.2 \%$ Bg 250
calli demonstrated resistance to glyphosate at 0.2\%. FAFLP analysis revealed
E11M32 marker was found to be a specific marker to identify the induced HR in rice.
The results of the study revealed that in vitro application of EMS on callus has ability
to develop HR rice calli.

Key words: EMS, Glyphosate, Seed culture, AFLP

\section{Introduction}

Rice is the staple food for more than half of the world population and for every one billion people added to the world population, an additional 100 million MT of rice needs to be produced every year [1]. In future, it is imperative that rice production continues to grow at least as rapidly as the population; thus application of biotechnology provide a good solution. Weeds are the major biological constraint in rice cultivation, which reduce the yield qualitatively and quantitatively. Therefore, it is important to control rice weeds to obtain a good yield [2]. Rice weeds account for a $30-40 \%$ yield loss (about 160-200 $\mathrm{kg} \mathrm{ha}^{-1}$ ) in spite of farmers investing US $\$ 40-60$ ha ${ }^{1}$ for herbicides [3]. Therefore, there is a need to take timely action to prevent destruction of paddy cultivation. Rice growers and consumers throughout the world could benefit from the introduction of herbicide resistant (HR) rice cultivars which selectively control weeds. HR crops provide additional crop choice, enabling implementation of alternate weed management tactics to target specific weeds while maintaining crop sequences. [4]. In general, HR crops may be favorable to the environment by allowing for flexible weed management compared to conventional systems. This may permit farmers to practice conservation tillage, and thereby reduce soil erosion [5].Other perceived benefits are the possibility to control 'hard-to-kill' weed species [4] and weed populations that have already evolved resistance to herbicides, especially those of the Echinochloa species. Weed management could also be improved by more efficient post-emergence control [6]. Introduction of HR rice could also bring areas heavily infested with weedy rice that have been abandoned back to rice production [7], allow long term crop rotations, reduce consumption of fossil fuels [8], and provide more rice grain without adding new land to production. Herbicide-tolerant crops in combination with their corresponding herbicides are able to control many weeds that cannot be or are less effectively controlled with other means. Most of the herbicide-tolerant mutants were developed through chemical mutagenesis followed by herbicide selection [9]. Among the chemical mutagens, Ethyl Methyl Sulphonate (EMS) is a strong chemical mutagen which can make the chromosome structure different [10]. Utilizing EMS mutation method, [11] developed 21 Brazilian rice lines that were resistant to glufosinate. [12] used EMS for the development of sulfonylurea resistant mutants of Arabidopsis thaliana and EMS were used to increase the probability of selecting resistant mutants in soybean $[13,14]$ and tobacco [15].

Genetic engineering of rice has made significant advances in the past few years [16] and HR transgenic crops have been the most widely used type of transgenic crops. 
Genetic engineering work to develop glyphosate resistant crops focused on three strategies: overproduction of EPSP synthase, introduction of a metabolic detoxification gene and introduction of an altered EPSP synthase enzyme with decreased affinity for glyphosate [17]. [18] were the first to report on studies with altered EPSP enzyme genes for glyphosate tolerance development in plants and several other glyphosate-resistant crops such as soybean, cotton, canola etc. were developed by introducing the CP4 gene from Agrobacterium sp., which encodes a resistant form of EPSPS [19]. However, the introduction of transgenic HR crops in developing countries and their impacts is a controversial issue. In Sri Lanka there are strict regulations and management of genetically modified organism (GMO) including genetically modified (GM) crops imported to Sri Lanka and produced within the country [20]. Since the herbicide resistance in crop plants can also be achieved by classical genetics to make stable resistant lines instead of a plant modified by genetic engineering, it is worthwhile to focus on a less controversial classical plant breeding approach.

Plant tissue culture represents the simplest of the biotechnologies available at present for crop improvement [21].The plants which are produced by tissue culture procedure are tested for their resistance to herbicide [22]. This procedure is repeated with increasing amounts of herbicide to provide an herbicide-tolerant/resistant plant tissue which is subsequently subjected to differentiating growth conditions to provide herbicide tolerant plants. These plants can be propagated vegetatively using tissue culture methods to produce additional plants of the same genetic constitution. The plants also can be sexually reproduced to provide seeds and plants which display inherited tolerance to the said herbicide [22]. The first herbicide tolerant plant developed in the laboratory was tobacco mutant plant, obtained through selection of cell lines in tissue culture [15]. Further, plants resistant to imidazolinone have been successfully produced by seed, microspore, pollen and callus mutagenesis and somatic cell selections in maize [23], canola [24], cotton [25], soybean [13] and wheat $[26,27]$.

Application of molecular markers in plant breeding programs has established the need for information on variation on DNA sequences [28]. Amplified Fragment Length Polymorphism (AFLP) is a relatively new DNA fingerprinting technique [29] which uses selective amplification of restriction fragments and that has the capacity to detect a higher number of loci and thus a higher rate of polymorphism in a single assay than RFLPs or RAPDs [30]. AFLP methodology has been employed in greater number of studies such as diversity, phylogeny, genomic linkage mapping, and identification of varieties, because of their effectiveness and reliability for studies [31,32,33]. A detailed RAPD analysis has been carried out on the glufosinate resistant and susceptible Brazilian rice lines produced via mutagens by [11].

As far as the studies related to induction of HR through chemical mutation of calli, there is an inadequacy of such research on inducing HR among cultivated rice varieties and development of HR rice varieties in Sri Lanka. Therefore, the present study was carried out to identify the mutagenic response of seed-derived rice calli to EMS and to evaluate HR in EMS treated rice calli. In addition, Fluorescent AFLP (FAFLP) analysis was performed for choosing possible molecular marker for identification and/or confirmation of induced HR under in vitro conditions

\section{Materials and methods \\ Callus induction}

Glyphosate susceptible rice variety, $\mathrm{Bg} 250$ was selected for the study, based on finding of a previous study [34].Glyphosate resistant traditional rice variety, Pachchaperumal was taken as the reference/control. Mature rice seeds were dehusked 
and surface disinfected after soaking for 1 minute in $70 \%$ ethanol and, subsequently seeds were washed with distilled water and Sodium Dodecyl benzene Sulphonate (Teepol) for 1 minute. Bleach-sterilization was carried out for 20 minutes in 50\% commercial bleach. Following three rinses with sterilized water, seeds were cultured (10 seeds/petridish) in solid MS medium for callus induction [35] supplemented with 2, 4-D, BAP, Kinetin and Myo Inositol. Cultures were incubated in a culture room maintaining at $25^{\circ} \mathrm{C} \pm 2^{\circ} \mathrm{C}$ in complete dark.

\section{Chemical mutagenesis}

When the calli were approximately $1-2 \mathrm{~mm}$ in diameter, they were transferred into falcon ${ }^{\mathrm{TM}} 50 \mathrm{ml}$ tubes containing $30 \mathrm{ml}$ of liquid $\mathrm{MS}$ media without 2,4D. Subsequently, the calli were immediately mutagenised by adding different concentrations of EMS $(0.0,0.1 \%, 0.2 \%, 0.3 \%$ and $0.4 \%$ v/v) (Sigma-Aldrich). Each treatment consisted of 10 calli and there were three replicates from each treatment. Culture tubes were covered with aluminum foil and placed on an orbital shaker (150 $\mathrm{rpm})$ for two hours. The incubated calli were rinsed 10 times with MS liquid medium and transferred to new tubes containing MS liquid media with 2, $4 \mathrm{D}$ and shaken (120 $\mathrm{rpm})$ for two more days $\left(28{ }^{\circ} \mathrm{C} \pm 2{ }^{\circ} \mathrm{C}\right.$, in darkness) (Serrat et al. 2014). The treated calli were subsequently sub-cultured on to MS medium containing NAA and Kinetin.Initial screening of viable/non-viable calli was carried out based on the changing of color in calli from creamy white (alive) color to brown (dead). The confirmation of cell viability was assayed by Tetrazolium chloride (1\% TTC) (Towill et al. 1975).

The survival percentages of calli as an indicator EMS tolerance were calculated according to the equation given below.

(1)

$$
\text { CSP } \%=\frac{\text { No.of viable calli }}{\text { No.of treated calli }} \times 100
$$

\section{Callus regeneration and glyphosate resistance}

Twenty sub-cultured callus were treated with $0.2 \%(\mathrm{v} / \mathrm{v})$ glyphosate solution after ten days and observed the characteristics of the callus compared to untreated callus. Regenerated shoots were also exposed to glyphosate and separately assayed for HR.

\section{AFLP Molecular study}

AFLP analysis was carried out on the mutated calli using 16 AFLP primer combinations. Genomic DNA was extracted from mutated calli using PhytoSpin ${ }^{\mathrm{TM}}$ Plant Genomic DNA extraction kit (Ceygen Biotech). AFLP analysis was performed as described by [29] with minor modifications.

One $\mu \mathrm{g}$ of DNA from each sample was digested with 5 units of EcoR1, 5 units of Mse 1 enzymes.The digested samples were incubated at $37^{\circ} \mathrm{C}$ for $3.5 \mathrm{~h}$. To the double digested DNA, EcoR1 adaptor $\left(10\right.$ pmol $\left.\mu 1^{-1}\right), M s e 1$ adapter $\left(10\right.$ pmol $\left.\mu 1^{-1}\right) 5 \mathrm{U}$ of T4 DNA ligase were added and the tubes were incubated overnight $(\sim 16)$ at $37^{\circ} \mathrm{C}$. After the ligation of adapters, $5 \mu \mathrm{l}$ of digested/ligated DNA were pre-amplified in $25 \mu \mathrm{l}$ reaction containing $2 \mu \mathrm{l}$ each of pre-amplification primers $(8 \mathrm{pmol} / \mu \mathrm{l}), 0.2$ mMdNTPs, 1X PCR buffer (Genscript, USA), and 1 unit of Taq DNA polymerase (Genscript, USA) (5 units/ $\mu$ l). PCR amplification was performed using the following 
cycle conditions. Denaturation at $94^{\circ} \mathrm{C}$ for $30 \mathrm{~s}$, annealing at $56^{\circ} \mathrm{C}$ for $60 \mathrm{~s}$, extension at $72{ }^{\circ} \mathrm{C}$ for $60 \mathrm{~s}$ and cycles were repeated for 30 times. The pre-amplification product was diluted $20 \mathrm{x}$ with sterile distilled water and used as a template for selective amplification. The selective amplification reaction was conducted in a final volume of $20 \mu \mathrm{l}$ containing $2 \mu \mathrm{l}$ of diluted pre-amplification PCR products, $0.6 \mu \mathrm{l}$ of EcoR 1 fluorescent (Fam,Pet,Vic,Ned) labeled primer $(8 \mathrm{pmol} / \mu \mathrm{l}), 0.6 \mu \mathrm{l}$ of $\mathrm{Mse} 1$ primer $(8$ pmol/ $\mu \mathrm{l}$ ), $0.2 \mathrm{mMdNTP}, 1 \mathrm{X}$ PCR buffer (Genscript, USA), and 1 unit of TaqDNA polymerase. The PCR amplification was carried out as follows: Denaturation at $94{ }^{\circ} \mathrm{C}$ for $30 \mathrm{~s}$, annealing at $65^{\circ} \mathrm{C}$ for $30 \mathrm{~s}$. in the first cycle and then the annealing temperature was reduced by $0.7^{\circ} \mathrm{C}$ per cycle for the next 12 cycles. Then the cycles were repeated 23 more times with the annealing temperature of $56^{\circ} \mathrm{C}$. Extension was at $72{ }^{\circ} \mathrm{C}$ for $60 \mathrm{~s}$ for all cycles.

A fluorescent labeled DNA size strand LIZ 600 with known fragments size was mixed with each $2.5 \mu 1$ amplified PCR products and $5 \mu 1$ of deionized formamide loading solution and $2.5 \mu 1$ of ultra-pure water. Then the samples were loaded in 96 well plates (Axygen Biosciences, USA). Samples were denatured at $95{ }^{\circ} \mathrm{C}$ for $2 \mathrm{~min}$., chilled immediately placing plate on ice. The denatured amplified products were separated through capillary electrophoresis Mega BACE 1000 automated DNA sequencer (GE Healthcare Life Sciences, USA). AFLP fragment analysis was performed with Genemapper ${ }^{\circledR} 4.1$ software.

\section{Results and discussion}

\section{Callus induction}

Callus induction was observed in $40 \%$ of rice seeds; callus developed from the scutellar region of the seeds and was visible 8 -12 days after culturing. [38] has reported the similar results conducting a study on phenotypic evaluation of scutellumderived calli in 'Indica' rice cultivars.

\section{Mutagenesis effect of different EMS concentrations}

First week after EMS treatment, no noticeable differences were detected in calli between the control and treatments. After 7-10 days of EMS treatment, 0.3 and $0.4 \%$ treated calli showed a certain degree of browning. The results indicated that the viability of seed-derived callus decreased when the EMS concentration increased (Figure 2). At $0.2 \%$ EMS concentration, approx. 50\% of the calli survived and the same concentration was selected for further studies.

\section{Glyphosate resistance in EMS treated callus}

Subsequent to the application of glyphosate, EMS-mutated calli indicated positive response for the Tetrazolium Chloride (TTC) test [37]. Sixty percent of the calli treated with EMS turned into red color following the staining process (Figure 3). The control treatment which was not mutated with EMS signified negative results and the color of the calli were not changed with staining. It indicated that glyphosate resistance has developed in the EMS-mutated callus compared to the control. Callus derived from Pachcaperumal seeds also showed positive results to TTC test without EMS mutation. The shoots regenerated from mutated calli also appeared healthy (Fig. 4). This finding is supporters by the findings of similar studies carried out elsewhere. The technique of mutation induction over the past 50 years has played a major role in the development of superior crop varieties [39]. Most of the herbicide-tolerant mutants were developed through chemical mutagenesis followed by herbicide selection such as Imidazolinone-resistant rice which was developed through chemically induced seed mutagenesis with EMS [40, 9]. Comparison of results with 
other studies carried out on the induction HR via mutagenesis of calli is limited and these finding could be considered as baseline information for future studies.

\section{AFLP Molecular Study}

The comparison of mutated and non-mutated calli, several fragments produced variation in the AFLP pattern. Out of the sixteen primer pairs used in the FAFLP analysis E11M32 primer combination clearly differentiated the mutated calli. The 80bp fragment from E11 + M13 primer (TGT AAA ACG ACG GCC AGT GAC TGC GTA CCA ATT CAC) and M32 primer (GAT GAG TCC TGA GTA AAA C) was found to be a specific marker for HR induced rice callus. Benefiting from molecular cloning and PCR techniques, DNA markers have now become a popular means for identification and authentication of plant and animal species[41]. DNAbased markers are less affected by age, physiological condition of samples and environmental factors of plant tissues. They are not tissue specific and thus can be detected at any phase of organism development [42].The identified AFLP marker in the present research is potentially useful in developing HR rice varieties and can imply in breeding programs in future. Use of plant tissue culture techniques in development of HR provides several benefits such as less labor intention and rapid propagation. There were no previous records on the induced herbicide resistance in rice varieties via classical breeding methods in Sri Lanka and this study emphasizes that there is a possibility of in vitro development of HR in local rice varieties.

\section{Conclusions}

Survival of calli was higher at lower EMS concentrations compare to higher concentrations in the mutated seed-derived rice calli. Results suggest that using a dose of 0.1 to $0.2 \%$ EMS can induce mutation in seed-derived calli. Mutated calli and the regenerated plantlets of $\mathrm{Bg} 250$ showed resistance to glyphosate at $0.2 \%$ concentration. AFLP analysis showed that 80bp fragment from E11 + M13 primer (TGT AAA ACG ACG GCC AGT GAC TGC GTA CCA ATT CAC) and M32 primer (GAT GAG TCC TGA GTA AAA C) was found to be a specific marker for HR induced callus. As there is a possibility of HR rice to apply lesser quantity of herbicides, lesser frequency of application and occupied to effective weed management, induced HR rice varieties have a higher potential in rice breeding programs leading to develop new HR rice varieties in future.

\section{Acknowledgment}

The research grant provided by the National Research Council, Sri Lanka (Grant No. NRC 12-037) is greatly appreciated and the proper guidance of Mrs. A.S.K. Abeysekara, Senior Research Officer, RRDI, Bathalagoda, Sri Lanka is also greatly acknowledge.

\section{References}

1. Hegde,S.andHegde,V.(2013).Assessment of Global Rice Production and Export Opportunity for Economic Development in Ethiopia.InternationalJournal of Science and Research (IJSR), India 2(6) : 257-260.

2. Labrada, R.(2007). Weedy and Wild Rice.Their Impact and Management.p.8-15.21 ${ }^{\text {st }}$ Asian Pacific Weed Science Society (APWSS) Conference, Colombo, Sri Lanka. 
3. Abeysekara, A. S. K., Nugaliyadda, L., Herath, H. M. S., Wickrame, U. B. and Iqbal, Y. B. (2010). Weedy Rice: a threat to direct seeded rice cultivation in Sri Lanka. Rice Congress, PGRC, Gannoruwa, Pp 17-18.

4. Beckie, H. J., K. N. Harker, L.M.Hall, S.I. Warwick, A.Légère, P.H.Sikkema, G.W Clayton, A.G.Thomas,J.Y. Leeson, G.SéguinSwartz and M.J.Simard. (2006). A decade of herbicide-resistant crops in Canada.Can. J. Pl. Sci, 86: 1243-1264.

5. Duke,S.O. (2005).Taking stock of herbicide-resistant crops ten years after introduction. Pest Management Science, 61: 211-218.

6. Wilcut J W, Coble H D, York A C, Monks D W. (1996). Theniche for herbicide-resistant crops in U.S. agriculture. In:Herbicide-resistant crops, agricultural, environmental, economic, regulatory, and technical aspects, pp. 213-230.

7. Croughan T. (1998).Herbicide resistant rice.US Patent andTrademark Office. US Patent 5,952,553.

8. Mannion A M. (1995).Agriculture, environment and biotechnology.Agriculture, Ecosystems and Environment,53:31-45.

9. Tan, S., Evans, R. R., Dahmer, M. L., Singh, B. K. and Shaner, D. L. (2005).Imidazoline-tolerant crops: history, current status and future. Pest Management Science, 61: 246-257.

10. Barro F, Fernandez-Escobar J, De La Vega M, Martin A (2001) Doubled haploid lines of Brassica carinata

with modified erucic acid content through mutagenesis by EMS treatment of isolated microspores. Plant Breed, 120(3):262-264.

11. Sandhu,S.S., Bastos,C.R.,Azini,L.E.,Neto, A.T., and Colombo, C. ( 2002) RAPD analysis of herbicide-resistant Brazilian rice lines produced via Mutagenesis. Genetics and Molecular Research 1: 359-370.

12. Haughn GW, Somerville C.(1986). Sulfonylurea-resistant mutants of Arabidopsis thaliana. Molecular and General Genetics, 204(3): 430-434.

13. Sebastian S, Fader G, Ulrich J, Forney D, Chaleff R. (1989).Semidominant soybean mutation for resistance to sulfonylurea herbicides. Crop Science, 29(6): 1403-1408.

14. Sebastian, S.A., Chaleff RS.(1987). Soybean mutants with increased tolerance for sulfonylurea herbicides. Crop science, 27(5): 948-952.

15. Chaleff R, Ray T.(1984). Herbicide-resistant mutants from tobacco cell cultures. Science, 223(4641): 1148-1151.

16. Christou P. (1994).Applications to plants. In: Yang N-S, Christou P(eds) Particle Bombardment Technology for Gene Transfer,pp. 17-198. Oxford University Press, Oxford/New York (1994).

17. Dill GM ( 2005).Glyphosate-resistant crops: history, status and future. Pest. Manag. Sci, 61: 219-224. 
18. Comai, L., Facciotti, D., Niatt, W.R., Thompson,G., Rose, R.E., and Stalker, D.M. (1985). Expression in plants of a mutant aroAgene from Salmonella typhinurium confers tolerance to glyphosate, Nature, 317: 741-744.

19. Padgette, S. R., Re, D. B., Barry, G. F., Eichholtz, D. E., Delannay, X., Fuchs, R. L., Kishore, G. M. and Fraley, R. T. (1996). New weed control opportunities: development of soybeans with a Roundup Ready gene. In: S. O. Duke (Ed), Herbicide-resistant crops: agricultural, environmental, economic, regulator, and technical aspects (pp. 53-84), CRC Press, Boca Raton, FL

20. National Bio-safety Framework of Sri Lanka (2005). Ministry of Environment and Natural Resources, Colombo, Sri Lanka. Pp. 1-68.

21. Sudhakar ,P.,SaradaMani,N. and Ramana,T. (2009).Long-Term Maintenance of Callus Cultures from Immature Embryo of Sorghum bicolor.World Journal of Agricultural Sciences, 5 (4): 415-421.

22. Mulwa, R. M. S. and Mwanza, L. M. (2006). Biotechnology approaches to developing herbicide tolerance/selectivity in crops. African Journal of Biotechnology, 5: 396-404.

23. Newhouse, K., B.K. Singh., D.L. Shaner., and M. Stidham. (1991). Mutation in corn (Zea mays L.) conferring resistance to imidazolinones. Theor. Appl. Genet, 83-65.

24. Swanson, E.B., Hergesell.,M.J., Arnoldo,M., Sippell,D.W., and Wang,R.S.C. (1989) . Microspore mutagenesis and selection: Canola plants with field tolerance to imidazolinones. Theor. Appl. Genet, 78:525-530.

25. Subramanian, M.V., Hung,H.Y ., Dias,J.M., Miner,V.W., Butler,J.H., and Jachetta,J.J.( 1990). Properties of mutant acetolactate synthase resistant to triazolo pyramidine sulfonanlilide. Plant Physiol, 94:239-244.

26. Newhouse, K., Smith,W., Starrett,M., Schaefer,T., and Singh.,B.K.(1992) . Tolerance to imidazolinones in wheat. Plant Physiol,100:882-886.

27. Pozniak, C.J., and P.J. Hucl.(2004). Genetic analyses of imidazolinone resistance in mutation-derived lines of common wheat. Crop Sci, 44:2330.

28. Bhagwat ,A., Krishna,T.G., and Bhatia, C.R. (1997). RAPD analysis of induced mutants of groundnut (Arachis hypogaea L.), J. Genet, 76:201208.

29. Vos, P., Hogers, R., Bleeker, M .,Vandelee, T.,Hornes, M., Fritjers, A.,pot, J., Peleman, J .,Kuiper, M., and Zabeau,M. (1995). AFLP: a new technique for DNA fingerprinting. Nucleic Acid Research, 23:44074414. 
30. Powell, W., Morgante, M., Andre, C., Hanafey, M., Vogel, J., Tingey, S., and Rafalski, A. (1996).The comparison of RFLP, RAPD, AFLP and SSR (microsatellite) markers for germplasm analysis. Molecular Breeding, 2:225-238.

31. Becker, J.,Vos, P., Kiuper, M., Salamini, F., and Heun, M. (1995).Combined mapping of AFLP and RFLP markers in barley. Mol. Gen. Genet,249:265-273.

32. Maughan, P.J., SaghaiMaroof, M.A., Buss, G.R., and Huestis, G.M. (1996). Amplified fragment length polymorphism (AFLP) in soybean: Species diversity, inheritance and near isogenetic line analysis. Theoretical Applied Genetics, 94:255-263.

33. Xu, R.Q.,Tomooka, N., and Vaughan, D.A. (2000). AFLP Markers for characterizing the azuki bean complex. Crop Science, 40:808-815.

34. Weerakoon,S.R.,Somaratne,S.,Wijerathne,R.D.G., Ekanayaka,E.M.S.I. (2013). Natural Herbicide Resistance (HR) to Broad-spectrum Herbicide, Glyphosate among Traditional and Inbread cultivated rice (Oryza sativa L) Varieties in Sri Lanka.PakisthanJournal of Biological Sciences, 16 (16):796-803.

35. Murashige, T., and Skoog, F. (1962). A Revised Medium for Rapid Growth and Bio Assays with Tobacco Tissue Cultures. Physiologia Plantarum, 15: 473-497.

36. Serrat, X., Esteban, R., Guibourt, N., Moysset, L., Nogués, S., and Lalanne, E. (2014). EMS mutagenesis in mature seed-derived rice calli as a new method for rapidly obtaining TILLING mutant populations. Plant Methods,10:5.1746-4811.

37. Towill, L.E., and Mazur,P.(1975).Studies on the reduction of 2,3,5triphenyltetrazolium chloride as a viability assay for plant tissue cultures. Canadian Journal of Botany, 53(11): 1097-1102.

38. Pazuki,A.,andSohani,M,M.(2013).Phenotypic evaluation of scutellumderived calluses in 'Indica' rice cultivars.ActaagriculturaeSlovenica, 101: 239-247.

39. Datta, S.K. (1997). Ornamental plants: role of mutation. New Delhi, Daya Books, 220p.

40. Gealy, D. R., Mitten, D. H., and Rutger, J. N. (2003). Gene flow between red rice (Oryza sativa) and herbicide-resistant rice (O. sativa): Implications for weed management. Weed Technology, 17: 627-645.

41. Gholizadeh,M.,and Mianji, G.R.(2007).Use of Microsatellite Markers in Poultry Research.International Journal of Poultry Science, 6 (2): 145-153.

42. Ganie,S.H., Upadhyay,P.,Das,S and Sharma,M.P.(2015). Authentication of medicinal plants by DNA markers.Plant Gene, 4 (2015) 83-99. 
(Tables \& Figures)

Table 1. AFLP primers used for the study

\begin{tabular}{ll}
\hline Oligo name & \multicolumn{1}{c}{ Oligo sequence } \\
\hline M13 +E10 & $\begin{array}{l}\text { 5' TGT AAA ACG ACG GCC AGT GAC TGC GTA CCA ATT } \\
\text { CAA 3' }\end{array}$ \\
M13 + E11 & $\begin{array}{l}\text { 5' TGT AAA ACG ACG GCC AGT GAC TGC GTA CCA ATT } \\
\text { CAC 3' }\end{array}$ \\
M13 + E12 & $\begin{array}{l}\text { 5' TGT AAA ACG ACG GCC AGT GAC TGC GTA CCA ATT } \\
\text { M13 + E13 }\end{array}$ \\
CAG 3 & CAT 3' AAA ACG ACG GCC AGT GAC TGC GTA CCA ATT \\
M31 & 5' GAT GAG TCC TGA GTA AAA A 3' \\
M32 & 5' GAT GAG TCC TGA GTA AAA C 3' \\
M33 & 5'GAT GAG TCC TGA GTA AAA G 3' \\
M34 & 5' GAT GAG TCC TGA GTA AAA T 3' \\
\hline
\end{tabular}

Figure 1: Different stages of callus induction.

(A) Callus induction at initial stage, (B) $12^{\text {th }}$ day (C) $25^{\text {th }}$ day
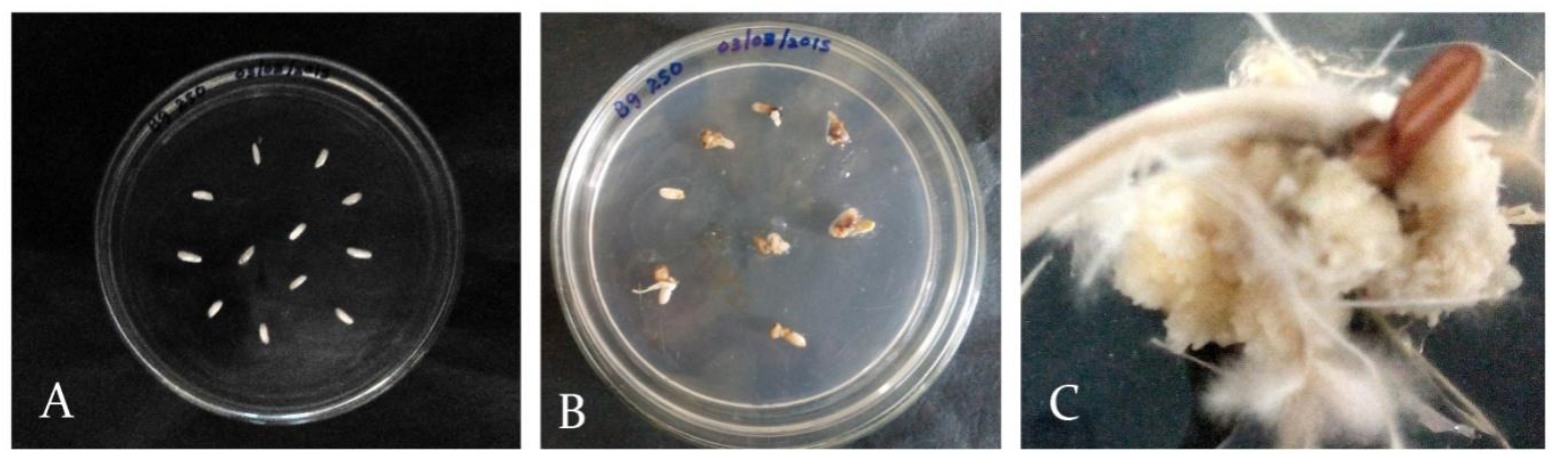

Figure2: Callus survival percentage at different concentrations of EMS

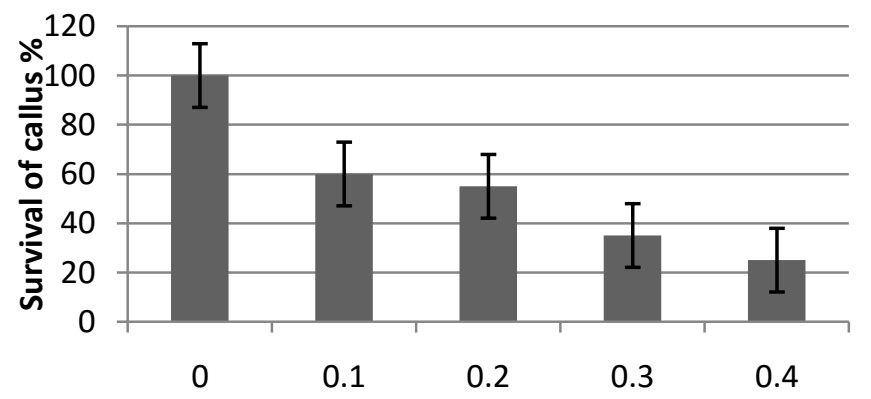

Different EMS concerntration 


\section{Figure3: Tetrazolium (TTC) staining.}

(A) Callus before staining (B) Viable callus showed red color after staining
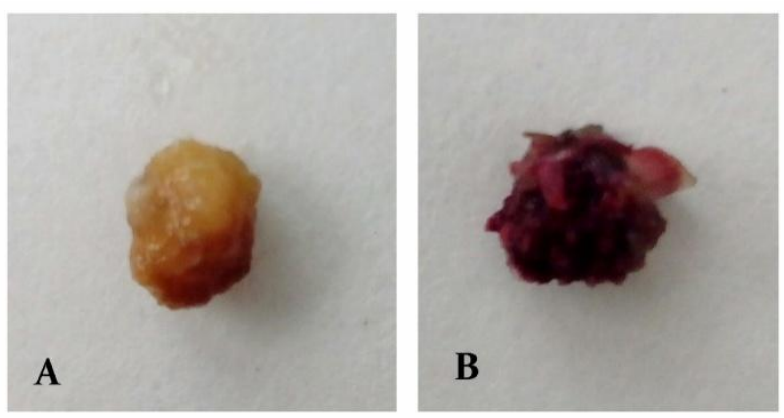

Figure 4: Regenerated plantlets with glyphosate resistance at different stages (A) Glyphosate treated callus (B) regenerated callus (C) regenerated plantlet

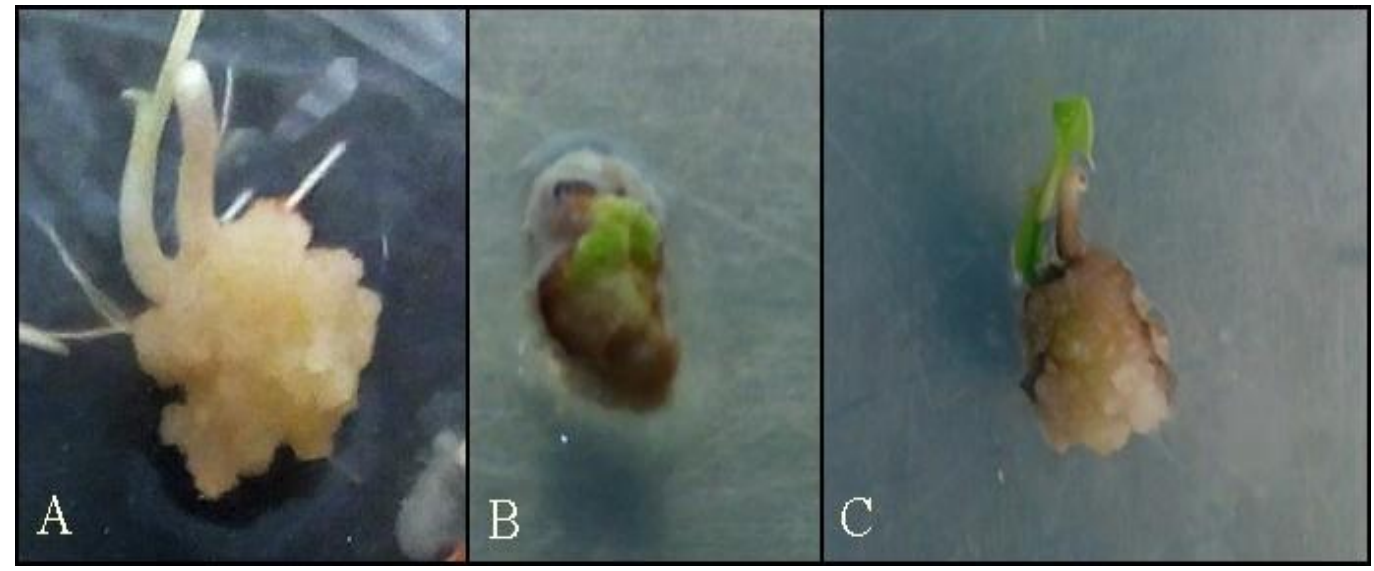

